\title{
A propósito de un linfoma anaplásico de células grandes con manifiesta peculiaridad de la relación clínica-patológica
}

\author{
E. VALLINA, F. FRESNO, E. SUÁREZ, A. R-GUARDADO, J. M. ARRIBAS \\ Cátedra de Patología Médica. Facultad de Medicina. Oviedo
}

\author{
ANAPLASTIC LARGE CELL LYMPHOMA. REPORT OF ON UNUSUAL \\ CASE
}

\section{RESUMEN}

Se describe un linfoma anaplásico de células grandes que reune todas las condiciones exigidas para incluirlo dentro de las formas descritas como "de tejido blando". Son llamativos en este caso, aparte de su escasa frecuencia en adultos, la grave repercusión sistémica del proceso, pese a no demostrarse la generalización del mismo, la ausencia de expresión de la proteína ALK1, frecuentemente positiva en las formas generalizadas, y la falta de respuesta a la poliquimioterapia. Creemos que este caso subraya la heterogenicidad del proceso en lo que se refiere a la relación clínico-patológica de este tipo de linfomas.

PALABRAS CLAVE: Linfoma. Anaplásico. Células grandes. Tejidos blandos.

\section{ABSTRACT}

An anaplastic large cell Iymphoma which fulfills all the criteria required for its inclusion among the soft tissue forms is reported. We point out in this case, in addition to its low frequency in adults, the seve re systemic involvement of the disorder with out generalization, the lack of expression of the ALK1 protein, frequently positive in the generalized forms and the absence of response to polichiomiotherapy. We think that this case emphasizes the heterogenicity if the disorder on the clinical pathologycal relation ship of this kind of Iymphomas.

KEY WORDS: Lymphoma. Anaplastic. Large cell. Soft tissues.

Vallina E, Fresno F, Suárez E, R-Guardado A, Arribas JM. A propósito de un linfoma anaplásico de células grandes con manifiesta peculiari dad de la relación clínica-patológica. An Med Interna (Madrid) 2002; 19: 527-529.

\section{INTRODUCCIÓN}

Los linfomas primarios de tejidos blandos son muy poco frecuentes, siendo la mayoría de los casos comunicados linfomas no Hodgkin, en los que predomina el tipo difuso de células grandes. Su incidencia supone aproximadamente el $1 \%$ de todos los tumores malignos de partes blandas. En una revisión de la AFIP (Armed Forces Institute of Pathology) (1-3) en un periodo de 20 años únicamente se identificaron 75 casos.

Los linfomas anaplásicos de células grandes (LACG) son clínica e histológicamente heterogéneos, lo que determina dificultades para su diagnóstico y para aceptarlos como una entidad específica (4).

Su variedad histológica condiciona su subdivisión en formas pleomórficas, monomórficas y con predominio de células pequeñas. También se han descrito casos asociados a la enfermedad de Hodgkin, morfologías que imitan a un sarcoma y otras descritas como linfohistiocíticas.
Clínicamente se dividieron en tipos sistémicos, variedades exclusivamente cutáneas y LACG localizados en tejidos blandos. Los tumores de tejidos blandos en el criterio de Chan no deben de afectar a la piel, tejido celular subcutáneo, hueso, gánglios linfáticos ni a ningún otro tejido en el momento del diagnóstico inicial. Generalmente se presentan como una masa de localización preferente en miembros inferiores en personas de mediana o avanzada edad $(5,6)$.

Junto a esto se han definido una serie de hechos inmunológicos y genéticos, como negatividad del antígeno leucocitario común (ALC), la positividad del CD30 (Ki-1) (7), del CD45Ro-UCHL-1, la presencia del antígeno epitelial de membrana EMA), la ausencia del CD15 y la translocación cromosómica (2:5) (p23:q35) con la formación del en de fusión nucleofosmin NPM)-quinasa de los linfomas anaplásicos (ALK) (8) y expresión de la proteína $\mathrm{ALK}_{1}$, detectable por métodos inmunohistoquímicos con anticuerpos monoclonales (9). Ninguno de estos hallazgos son observables en el $100 \%$ de los casos,

Trabajo aceptado: 20 de junio de 2001

Correspondencia: Emilio Vallina Álvarez. Servicio de Medicina Interna. Hospital Central de Asturias. Facultad de Medicina. Celestino Villamil, s/n. 33006 Oviedo 
como veremos, pero este conjunto de determinaciones es muy útil no sólo para encuadrar el linfoma como LACG, sino, como en el caso de la ALK, para intentar establecer una correlación clínicahistológica (6).

La mayoría de los LCG son de naturaleza B y han sido excluidos de este grupo en la clasificación REAL e incluidos en el grupo de los linfoma B de células grandes no hendidas difusos (7). Por lo tanto, verdaderos LACG han de ser de estirpe $\mathrm{T}$ y ofrecen lógicamente una incidencia mucho más escasa que la descrita para todos los linfomas de células grandes (10).

En relación con estos hechos describimos un genuino linfoma anaplásico de células grandes, que presenta múltiples peculiaridades, las cuales en nuestra opinión subrayan aún más la heterogenicidad de este tipo de procesos.

\section{CASO APORTADO}

Se trata de un paciente varón, de 77 años, con antecedentes de tuberculosis pulmonar y renal hace 30 años. Aparte de la realización de una nefrectomía derecha no puede especificar el tipo de tratamiento médico antituberculoso realizado. Fumador de 1,5 a 2 paquetes al día.

Ingresa en razón de un cuadro de anorexia, pérdida de $6 \mathrm{~kg}$ en los últimos meses y fiebre de $39^{\circ}$ de más de 3 semanas de evolución. El ingreso inicial tuvo lugar en el Servicio de Neumología por sospecha de reactivación de su antiguo proceso fímico, pero, una vez descartada esa posibilidad, fue trasladado al servicio de Medicina Interna. En la anamnesis por sistemas destaca un dolor de tipo mecánico muy inespecífico en la raíz del muslo derecho.

En la exploración física destacan un estado de nutrición deficiente, un enfisema torácico y escasos roncus y estertores burbujosos diseminados por la superficie torácica. Cifras tensionales oscilantes alrededor de 120/80 $\mathrm{mm}$ de $\mathrm{Hg}$.

En la exploración analítica sistemática se demuestran: a) VSG centenaria; b) parámetros de nutrición deficiente colesterolemia de $82 \mathrm{mg} \%$, albuminemia de $29 \%$ ); c) hipergammaglobulinemia policlonal del 35\% para unas proteínas totales de $6,4 \mathrm{~g} \%$; d) instauración progresiva de una anemia normocítica y normocroma a partir de $11 \mathrm{~g}$ $\%$ hasta $7,5 \mathrm{~g} \%$; e) leucocitos totales oscilantes entre 5 y 16.000 con granulocitosis en la fase terminal; f) en esta misma fase cultivo de orina positivo de más de 100.000 colonias de E. coli; g) tras iniciales valores normales funcionales hepáticos, en las fases tardías de su estancia en este centro hiperbilirrubinemia de $1,63 \mathrm{mg} \%$ con discretas elevaciones de las cifras de fosfatasa alcalina y de gammaglutamiltranspeptidasa y con normalidad persistente de transaminasas, hechos que fueron atribuidos a la medicación antitérmica y antiálgica; h) los estudios hormonales sistemáticos demostraron un hipogonadismo hipogonadotrópico con indemnidad del resto de los ejes. Resto de exploración analítica sistemática (glucemias, uremias, B12 y ácido fólico en sangre, ionogramas, marcadores tumorales, anticuerpos antinucleares y anticitoplásmicos ANCA y estudio de coagulación) no llamativo.

Los hemocultivos fueron repetidas veces negativos. Las serologías frente a virus, brucellas, leptospiras, legionellas, coxiellas, micoplasmas y toxoplasmas no ofrecieron títulos significativos ni incrementos posteriores de los mismos. La investigación de BK en esputos, médula ósea y tejido hepático resultó repetidas veces negativa. Papanicolau de esputos sin indicios de malignidad.

Los estudios radiológicos de tórax y la TAC de la misma zona evidenciaron la existencia de lesiones de aspecto fibroso de tipo crónico-residual en ambos vértices pulmonares, bronquiectasias, enfisema pulmonar, calcificaciones pleurales en las base derecha y dilatación de la aorta ascendente de más de $4 \mathrm{~cm}$.

La ecografía y la TAC abdominales demostraron una nefrecto- mía derecha, un riñón izquierdo grande compensador, una ateromatosis aórtica y una pequeña imagen excrecente vesical que correspondía a la próstata, valorada por el Servicio de Urología como de tamaño y funcionalismo normales.

La gastroscopia fue informada como una gastritis crónica superficial, presencia de úlcera duodenal y duodenitis. Enema opaco normal.

Los estudios electrocardiográficos fueron normales, si bien desarrolló un episodio de fibrilación auricular de corta duración.

En la gammagrafía ósea existían hipercaptaciones de distinto significado: una en la cresta iliaca izquierda era evidentemente posttraumática, otra en la cadera derecha correspondía a una coxartrosis y una tercera en el maxilar inferior derecho estaba en relación con un proceso inflamatorio dentario.

En la TAC cerebral se observaron pequeños infartos lacunares en los ganglios de la base sin otras alteraciones de interés.

Los estudios histológicos de médula ósea y de hígado resultaron anodinos sin hallazgos patológicos dignos de mención.

La resonancia magnética del muslo derecho demostró una masa en la cara posterior con áreas necróticas de 11 x 6 × $3 \mathrm{~cm}$ (Fig. 1 ).

Se realizo PAAF de la tumoración descrita con informe citológico de positividad para malignidad sin que se pudiera precisar estirpe, sugiriéndose la posibilidad de un histiocitoma maligno pleomórfico.

Se procedió a la exéresis quirúrgica de la masa citada por sospecha de sarcoma de partes blandas. El diagnóstico anatomopatológico final de la pieza fue el de linfoma anaplásico de partes blandas inmunofenotipo T ALK y Ki-1-positivo (Fig. 2).

Junto a los tratamientos ocasionales antitérmico (por probable

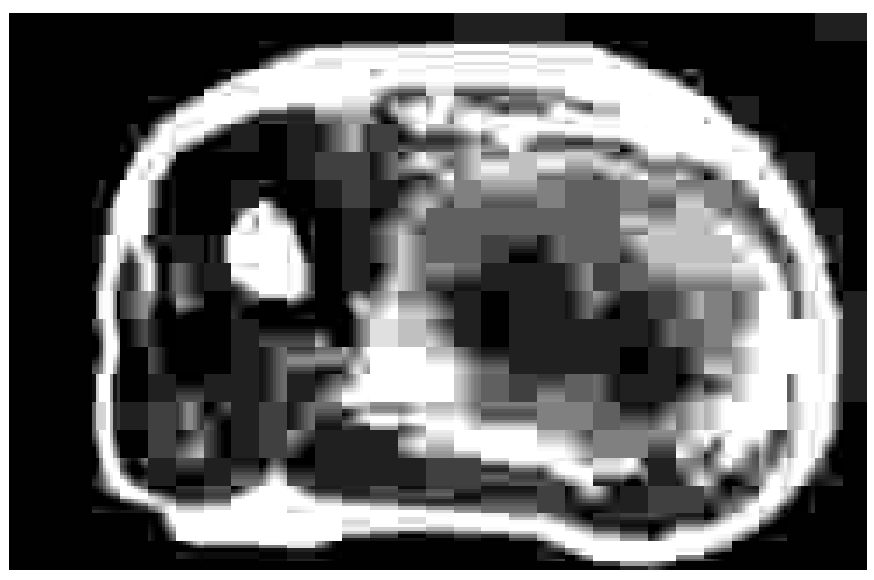

Fig. 1. Resonancia magnética nuclear. Corte axial en T1 tras administración de gadolinio.

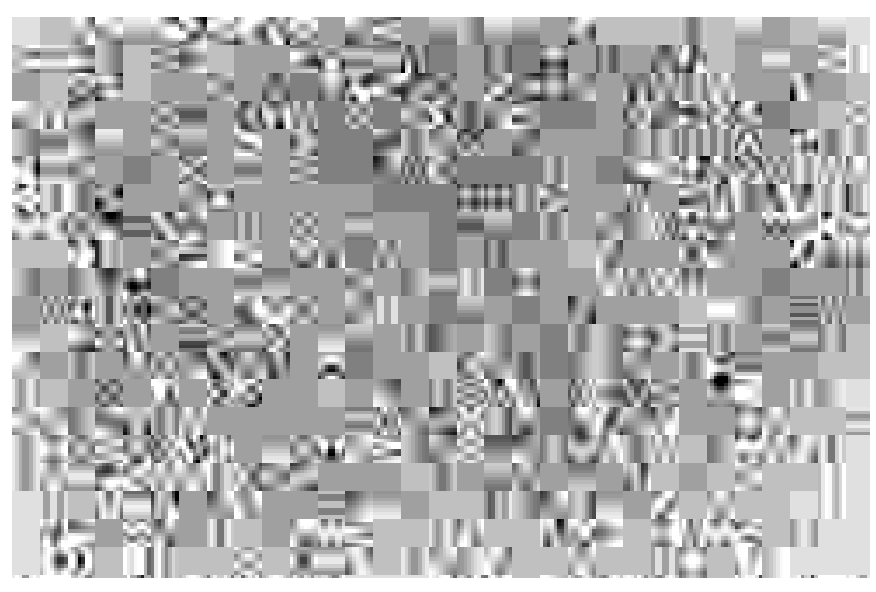

Fig. 2. LACG. Crecimiento fusiforme pseudo-sarcomatoso (200x). 
fiebre paraneoplásica, pero sin obtener respuesta), la terapéutica oportuna de su ulcus duodenal y de su infección urinaria, transfusiones sanguíneas y tratamientos sintomáticos diversos, tras el diagnóstico de linfoma anaplásico de células grandes de tejido blando, aunque ya resecado, dada la repercusión general del cuadro clínico, fue trasladado al servicio de Hematología donde se inició tratamiento poliquimioterápico CNOP sin respuesta, evolucionando el paciente al exitus dentro de un cuadro de caquexia y de fiebre ininterrumpida.

\section{DISCUSIÓN}

En nuestro caso las células tumorales mostraban una morfología fusiforme con áreas en las que se ordenaban en fascículos con un patrón de crecimiento de tipo estoriforme, es decir la histología del nódulo localizado en el muslo derecho sugería un sarcoma, pero los datos siguientes aseguraron la naturaleza del linfoma anaplásico de células grandes:

1.- Positividad de Ki-1.

2 - Positividad UCHL-1.

3.- Naturaleza linfomatosa $\mathrm{T}$ del proceso.

El caso constituye, pues, una variante de aspecto sarcomatoide de LACG1 (11).

La ausencia de adenopatías y de demostración de afectación de órganos internos en la completa exploración sistemática realizada permite encasillar este proceso como linfoma anaplásico de células grandes de tejido blando, al ser una manifestación única, no identificarse estructuras ganglionares linfáticas en la lesión y no estar afectados ni la piel ni el esqueleto, pues éstas son las condiciones de Chan para definirlo de ese modo (5).

$\mathrm{Su}$ pronóstico se ha considerado como muy favorable (más del $80 \%$ de pacientes se encuentran libres de tumor a los 6 años). Sin embargo, aquel empeora, si se detecta enfermedad en otra localización durante un periodo de 3 meses tras el diagnóstico inicial.

\section{Bibliografía}

1. Lanham GR, Weiss SW, Enzinger FM. Malignant Iymphoma, a study of 75 cases presenting in soft tissue. Am J Surg Pathol 1989; 13: 1-10.

2. Travis WD, Banks PM, Reiman HM. Primary extranodal soft tissue lymphoma of the extremities. Am J Surg Pathol 1987; 11: 359-366.

3. Schewalke MA, Rodil JV, Vezeridis MP. Primaruy Lymphoma arising in skeletal muscle. Eur J Surg Oncol 1990; 16: 70-73.

4. Kinney MC, Kadin ME. The patholoogic and clinical spectrum of anaplastic large cell lymphoma and correlation with ALK gene dysregulation. Am J Clin Pathol 1999; 111: 1 Suppl 1, 56-67.

5. Chan JKC. Soft tissue lymphomas and their mimickers. International Congress of IAP. Long Course 1994. Queen Elizabeth Hospital, Hong Kong.

6. Chan JKC. Anaplastic large cell lymphoma: redefining its morphologic spectrum and importance of recognition of the ALK-positive subset. Advances in Anatomic Pathology 1998; 5: 281-313.

7. Stein H, Mason DY, Gerdes J, et al. The expression of the Hodgkin s disease associated antigen $\mathrm{Ki}-1$ in reactive and neoplastic lymphoid tissue: evidence that Red-Stemberg cells and histiocytic malignancies are derived from activated lumphoid cells. Blood 1985; 66: 848-858

8. Morris SW, Kirstein MN, Valentine MB, et al. Fusion of a kinase gene, ALK1 to a nucleolar protein gene, NPM, in non-Hodgkin s lymphoma. Science 1994; 263: 1281-1284.

9. Pulford K, Lamant L, Morris SW, et al. Detection of ALK and NPMAL1K proteins in normal and neoplastic cells with the monoclonal antibody ALK. Blood 1997; 989: 1394.

10. Noorduyn LA, de Bruin PC, van Heerde P, et al. Relation of CD30 expression to survival and morphology in large cell lymphomas. J Clin
Con todo ha de tenerse en cuenta que estos LACG de tejido blando se comportan como agresivos y deben de ser tratados como tales, pero tiene a menudo buena respuesta. Si se les trata con poliquimioterapia, el índice de supervivencia a los 5 años es del 65 al $85 \%(5,12,13)$.

Pese a tratarse de un LACG de tejido blando el paciente ofrecía serias manifestaciones generales, como fiebre persistente, gran anorexia, manifiesto adelgazamiento y, en general, un deterioro tremendamente preocupante desde su ingreso. Este comportamiento tan agresivo es el descrito típicamente en los LACG de tipo primario sistémico. Incluso esta variedad primaria sistémica presenta a los 5 años del tratamiento poliquimioterápico índices de supervivencia del 60$70 \%$, lo que contrasta con la absoluta falta de respuesta de nuestro caso.

En la formas de LACG de tipo sistémico primario es habitual la translocación 2-5 y la reacción positiva inmunohistoquímica de la ALK en el 60-85\% de los casos , pero nuestro paciente era negativo al respecto, como se observa comúnmente en la formas primarias localizadas de los tejidos blandos.

En resumen: es llamativo que un linfoma anaplásico de células grandes, con todas las condiciones que se exigen para incluirlo como tal entre las formas localizadas de tejido blando, presente una sintomatología general tan agresiva, una reacción negativa para la ALK1 y una falta de respuesta a la poliquimioterapia.

Estas peculiaridades de nuestro caso clínico creemos que añaden mayor heterogenicidad a la ya descrita hasta ahora en la relación clínica-patológica de este tipo de linfomas.

También queremos recordar que debemos incluir la posibilidad de un linfoma, cuando estudiemos una neoplasia maligna de tejidos blandos, aunque presente una citología pleomórfica, un patrón estoriforme o cambios mixoides.

Pathol 1994; 47: 33-37.

11. Chan JKC, Buchanan R, Fletcher CDM. Sarcomatoid varient of anaplastic large cell Ki-1 lymphoma, report of a case. Am J Surg Pathol 1990; 14: 983-988

12. Fannin R, Silvestri F, Geromin A, et al. Primary systemic CD30 Kl positive anaplastic large cell lymphoma of the adult sequential intensive treatment with the F-MACHOP regimen (radiotherapy) and autologous bone marrow transplantation. Blood 1996; 87: 1243-1248.

13. Filippa DA, Ladanyi $\mathrm{M}$, Wollner $\mathrm{N}$, et al. C30 $\mathrm{Kl}$ positive malignant lymphomas: clinical, immunophenotypic, histologic and genetic characteristics and differences with Hodgkin s disease. Blood 1996; 87: 29052917.

14. Falini B, Bigerna B, Fizzotti M, et al. ALK expression defines a distinct group of T/null lymphomas ALK lymphomas) with a wide morphological spectrum. Am J Pathol 1998; 153: 875-876.

15. Benharroch D, Meguerian-Bedoyan Z, Lamant L, et al. ALK-positive lymphoma: a single disease with a broad spectrum of morphology. Blood 1998; 91: 2076-2084.

16. Nahamura S, Shiota M, Nakagawa A, et al. Anaplastic large cell lymphoma: a distinct molecular pathologic entity: a reappraisal with special reference to p801NPM/ALK) expression. Am J Surg Pathol 1997; 21:1420-1432.

17. Pulford K, Lamant L, Morris SW, et al. Detection of anaplastic lymphoma kinase ALK) and nucleolar protein nucleophosmin (NPM)-ALK proteins in normal and neoplastic cells with the monoclonal antibody ALK1. Blood 1997; 89: 1394-1404. 